\title{
Ambiente de Autoria de Jogos Locativos de Decisão para o Desenvolvimento de Habilidades de Tomada de Decisão
}

\author{
${ }^{1}$ Roberto Guimarães Morati Junior, ${ }^{1}$ Orivaldo de Lira Tavares, ${ }^{2}$ Crediné Silva de \\ Menezes \\ ${ }^{1}$ Departamento de Informática - Universidade Federal do Espírito Santo (UFES) \\ Caixa Postal 01.9011 - 29.075-910 - Vitória - ES - Brasil \\ ${ }^{2}$ Instituto de Informática - Universidade Federal do Rio Grande do Sul (UFRGS) \\ Caixa Postal 15.064 - 91.501-970 - Porto Alegre - RS - Brasil \\ \{robertomorati, credine\}@gmail.com, \{tavares\}@inf.ufes.br
}

\begin{abstract}
Resumo. De modo a contribuir com a criação de oportunidades para promover o desenvolvimento de habilidades de tomada de decisão em diferentes situações, este artigo apresenta a concepção de um ambiente que permite a construção de uma classe específica de jogos locativos, chamada de Jogos Locativos de Decisão. Esse artigo busca contribuições que impactam em três áreas de conhecimento: computação, psicologia e educação.
\end{abstract}

Palavras-chave: Aprendizagem - Processo Decisório, Métodos de Simulação, Realidade Aumentada, Jogos Locativos de Decisão, Computação Pervasiva.

\section{Introdução}

A todo tempo em nossas vidas tomamos decisões, e essa é uma das habilidades mais evidente no ser humano [March, 1994]. Decisões podem ser simples, como correr ou não para pegar um ônibus, ou mais complexas como escolher a casa onde morar. Ainda, podemos tomar decisões de alto risco. Por exemplo, decisões que são cruciais para o resultado de uma missão militar, ou em cenários onde acidentes podem acontecer, como, na construção civil. As decisões estão presentes no nosso dia a dia. Entretanto, os seres humanos normalmente tomam decisões baseados em emoções, o que pode não ser a melhor maneira, ou, não sabem como tomar boas decisões. Nesse contexto, a escola pode assumir um importante papel no aperfeiçoamento da habilidade de tomada de decisão, provendo oportunidades de tomada de decisão em ambientes simulados.

A par do exposto, é importante saber como ajudar seres humanos a tomar melhores decisões. Nesse contexto, a premissa principal é que o desenvolvimento das habilidades de tomada de decisão acontece com o aumento progressivo da consciência de que o uso de informações de experiências anteriores permite melhorar a qualidade das decisões tomadas [Klein et. al., 1993].

Com o propósito de desenvolver habilidades de tomada de decisão, jogos sérios têm sido constantemente explorados. Caird-Daley et al., [2009] apresentam o uso de jogos sérios para ensinar cadetes novatos a aprenderem a tomarem melhores decisões, no contexto militar. Já, Prasolova-Førland et al., [2013] apresenta o uso de jogos sérios para treinamento da tomada de decisão com base na conscientização cultural sobre o Afeganistão. Entretanto, 
esses jogos usam cenários e situações limitados para os jogadores sem a possibilidade de adaptá-los para outros contextos. Adicionalmente, tem-se uma interação social limitada, uma vez que a interação não ocorre naturalmente.

Com o intuito de viabilizar a criação de oportunidades para promover a tomada de decisão, este artigo apresenta um ambiente denominado Ambiente de Autoria de Jogos Locativos de Decisão (AutEnvLDG - Authoring Environment for Location Decision Games) para a construção de diferentes cenários para desenvolver habilidades de tomada de decisão em diferentes situações. Além disso, é importante enfatizar que esse ambiente permite a construção de jogos locativos com características educacionais para outros contextos. Por exemplo, a construção de um jogo para aprendizagem sobre a história de uma determinada área geográfica, ou, aprendizagem de uma área particular da biologia, como o Reino das Plantas (classificação de plantas) em um bosque.

Para sustentar essa proposta, o restante do artigo está organizado da seguinte forma: Na Seção 2 é apresentado o conceito de Jogos Locativos de Decisão (LDG). Seção 3 apresenta a caracterização do problema. Seção 4 apresenta a arquitetura do ambiente AutEnvLDG. Seção 5 apresenta o Ambiente de Autoria de Jogos Locativos de Decisão. Seção 6 apresenta um exemplo de utilização. A Seção 7 apresenta conclusões e trabalhos futuros.

\section{Jogos Locativos de Decisão}

Jogos Locativos de Decisão são aqueles onde elementos do mundo real e suas características compõem o cenário do jogo, usam posicionamento por meio do GPS e a inclusão de elementos do mundo virtual no mundo real [Morati Junior et al, 2014]. Esses elementos são percebidos visualmente pelos jogadores por meio de seus dispositivos móveis.

Os LDGs permitem que a interação entre os jogadores aconteça com naturalidade, além de combinar cenários e situações que reagem com as posições dos jogadores, de modo a permitir que o jogo tenha as seguintes características [Morati Junior et al, 2014]: Ambiente Dinâmico: elementos (personagens e monstros, por exemplo) devem ter um comportamento autônomo no cenário do jogo; Tempo: impor um determinado tempo para o jogador coletar um item ou cumprir uma missão, exigindo assim que o jogador planeje rapidamente suas decisões; Incertezas: o comportamento autônomo dos elementos do jogo faz com que o jogador tome decisões por meio de informações incertas. Colaboração: permitir aos jogadores dialogarem entre si para tomarem decisões colaborativas, bem como discutir sobre experiências. Para isso, o jogo deve permitir aos jogadores interpretar diferentes personagens; Sugestões: cada cenário/situação do jogo deve possuir uma ou mais sugestões. Sugestões são elementos de percepção do ambiente que auxiliam nas decisões. As sugestões permitem ao jogador contextualizar suas escolhas de ações provenientes de uma decisão; Enredo: Cada evento do jogo gerado por uma decisão deve ter um ou mais Enredo(s) associado(s). Enredo inclui elementos de texto, imagem, áudio ou objeto do jogo. Esses elementos são importantes, pois permitem ao jogador contextualizar e entender melhor o resultado de suas decisões. Além disso, esses elementos compõem a estória do jogo, permitindo ao jogador contextualizar e entender melhor o resultado de suas decisões. 
Essas características permitem o desenvolvimento de habilidades de tomada de decisão conceituadas a partir do modelo Tomada de Decisão baseada em Reconhecimento (RPD - Recognition-primed Decison Making) [Klein et. al,, 1993], a saber: Reconhecimento de Situação: o tomador de decisão reconhece a situação como sendo familiar ou não, levando assim a ações típicas; Avaliação de um Conjunto de Opções: nesta fase o tomador de decisão faz avaliação das possíveis ações, sendo as ações típicas da situação. O processo de análise das ações é feito por meio de uma simulação mental; Simulação Mental: nesta o tomador de decisão simula as possíveis etapas, resultados, possíveis problemas a serem encontrados e se esses problemas podem ser tratados.

\section{Descrição do Problema}

Entre os ambientes para construção e experimentação de jogos locativos ${ }^{1}$, tem-se o fAR-Play (A framework to develop Augmented/Alternate Reality Games) que no momento só disponibiliza um ambiente para experimentar os jogos criados e o ARIS (Augmented Reality and Interactive Storytelling) que é tido como um grande avanço na concepção de jogos locativos [GUTIERREZ et al,. 2011] e [ARIS, 2013]. Porém, esses ambientes apresentam deficiências que podem limitar a construção de jogos locativos para contribuir com o desenvolvimento de habilidades de tomada de decisão.

Para um jogador desenvolver habilidades para a tomada de decisão é necessário que o jogo apresente um ambiente dinâmico, ou seja, nesse jogo as seguintes características devem ser contempladas [March, 1994]: os elementos do jogo devem ter um comportamento autônomo; as situações do jogo devem ter limitação de tempo, deve ser possível que os jogadores possam colaborar entre si, bem como interagirem com Personagens Não Jogáveis (NPCs - Non-player Characters) ${ }^{2}$. Por fim, os NPCs também devem representar personagens que tenham por objetivo dificultar a aventura, por exemplo, por meio de falsas dicas para o jogador. Essas características, apesar de importantes para a tomada de decisão, não são tratadas nos ambiente ARIS e fAR-Play. Deste modo, percebemos o desafio de construirmos LDGs.

\section{Arquitetura do Ambiente AutEnvLDG}

O desenvolvimento consiste, basicamente, na definição de layouts das telas a serem exibidos para o usuário por meio de eventos usando Python e o framework Django ${ }^{3}$. Adicionalmente, usamos o Bootstrap, um framework para design de aplicação com HTML 5, de modo a permitir que o layout da ambiente se adeque de acordo com as resoluções das telas dos dispositivos. Além disso, para permitir o uso do ambiente em diversos dispositivos, nós optamos por utilizar a API versão 3.0 do Google $M_{a p s}{ }^{4}$, baseada em HTML 5.

\footnotetext{
${ }^{1}$ Jogos locativos: são jogos jogados por meio de um dispositivo móvel por meio de GPS no mundo real [CHOEK et al., 2004].

${ }^{2}$ Veja: http://en.wikipedia.org/wiki/Non-player_character

${ }^{3}$ Veja: https://www.djangoproject.com/

${ }^{4}$ Veja: https://developers.google.com/maps/documentation/javascript/tutorial?hl=tr
} 
A Figura 1 apresenta a arquitetura do ambiente para a construção de LDG, bem como as tecnologias usadas em cada elemento da arquitetura. Em síntese, a arquitetura é dividida em dois módulos principais: o lado do servidor, composto pelos Editores, que são denominadas Apps (Aplicações) que acessam o Banco de Dados durante a criação de uma determinada aventura, e a lado do cliente, onde, estão os templates que são acessados por diferentes tipos de dispositivos, de modo a possibilitar o uso dos editores. Ainda, tem-se o WSGI (Web Server Gateway Interface) que é uma interface entre web servers e frameworks para a linguagem Python.

Esse ambiente tem como propósito fundamental permitir a construção de jogos que utilizem cenários do mundo real e objetos virtuais para criar situações que exija tomada de decisão. A seguir são descritos os editores que compõem o ambiente AutEnvLDG. É válido citar que a descrição dos editores teve de ser resumida, devido à limitação de páginas.

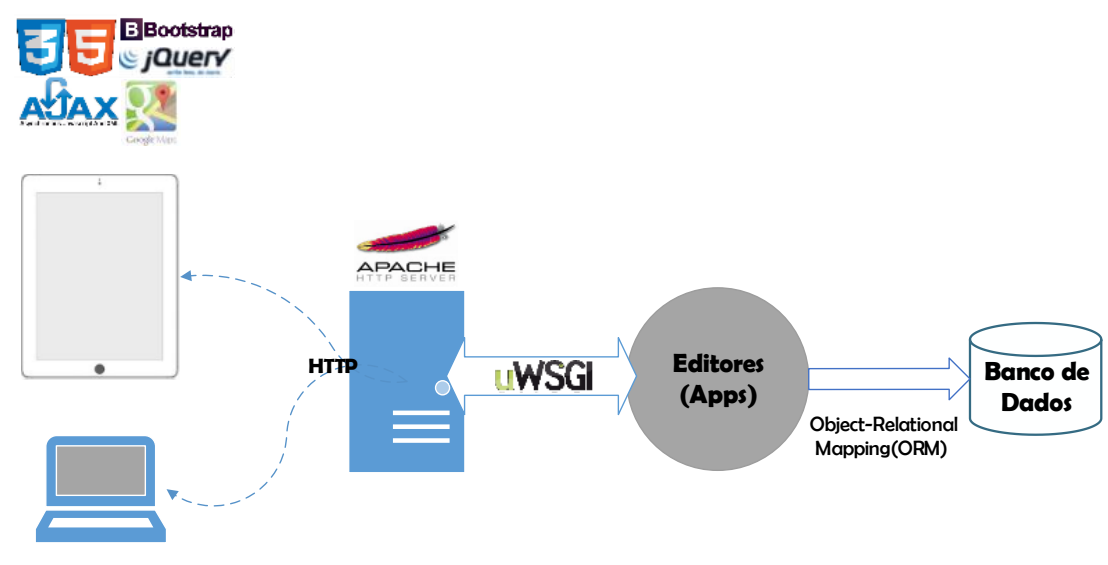

Figura 1: Arquitetura do ambiente AutEnvLDG

\section{AutEnvLDG: Ambiente de Autoria de Jogos Locativos de Decisão}

Esse ambiente tem como propósito fundamental permitir a construção de LDGs. A seguir são descritos os editores que compõem o ambiente AutEnvLDG. É válido citar que a descrição dos editores teve de ser resumida, devido à limitação de páginas.

\subsection{Editor de Aventuras}

O editor de aventuras admite a criação de aventuras e edição do cenário das aventuras. Uma aventura possui: nome, descrição sobre seu propósito, data e hora de início e término, e sua localização geográfica. Esse editor possibilita a edição de diferentes aventuras.

\subsection{Editor de Objetos}

O editor de objetos admite a criação de objetos em 2D e 3D. Assim, o jogador pode optar por visualizar o jogo por meio do Google Maps ou através da câmera do dispositivo móvel, onde o jogador visualiza objetos 2D ou 3D de fato no mundo real. Adicionalmente, esses objetos são símbolos que contribuem contribuir com a aprendizagem, atendendo ao Semiotic Principle [Gee, 2003]. 
Ao criar uma aventura, quando o objeto é carregado para o mapa, esse se torna uma instância de objeto. Uma instância de objeto possui nome, posição geográfica, proximidade ${ }^{5}$, encenação ${ }^{6}$, diálogos de conversação por meio de script, e sugestão, sendo que a sugestão também possui um atributo proximidade que indica a distância necessária para o jogador perceber a sugestão. A sugestão é um elemento de percepção que permite que os jogadores possam se lembrar de experiências passadas para tomar decisões mais eficientes. A Figura 2 apresenta um script de diálogo, onde tempos o diálogo que acontece entre uma instância de objeto (NPC) e o jogador.

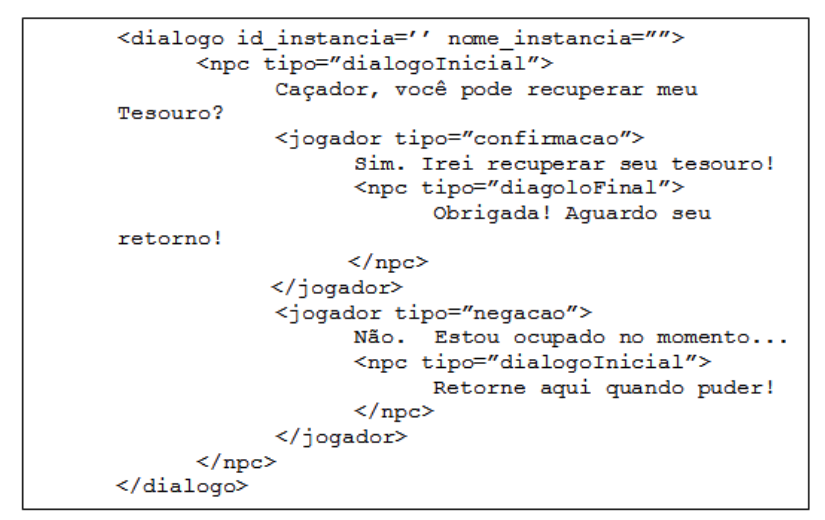

Figura 2:Script de Diálogo

\subsection{Editor de Jogadores}

Esse editor admite a criação de avatares para uma determinada aventura para serem usados pelo jogador com o dispositivo móvel. Essa flexibilidade é importante para um ambiente de tomada de decisão, pois permite que o jogador possa interagir com outros jogadores de forma colaborativa ou competitiva. Nesse contexto, os jogadores podem discutir e aprender a tomar decisões colaborativas.

\subsection{Editor de Missões}

O editor de missões admite a criação de missões e condições. Uma missão possui nome, descrição e o tempo necessário para sua conclusão, ainda, uma missão pode possuir um elemento de Enredo, descrito na definição de LDG. A criação de condições se dá por meio de triplas. Elas servem para compor missões, por exemplo, para completar uma missão, $n$ condições devem ser satisfeitas. Os tipos de condições são:

- <instancia>:<ligação>:<instancia>: a condição pode ser a combinação das instâncias de objetos. Por exemplo, o jogador em sua aventura deve obter o Tesouro e uma Caixa para guardar o tesouro. Deste modo, a condição para verificar se o jogador guardou o Tesouro na Caixa é: (Tesouro combinado Caixa).

- <avatar>:<ligação>:<instancia>: a condição pode ser a junção de um avatar com uma ação sobre um objeto. Por exemplo, em uma determinada aventura o jogador

\footnotetext{
${ }^{5}$ Proximidade: é a distância em metros (raio) que indica quando o jogador está próximo de um perigo, por exemplo Cascumpus. Ou próximo da sugestão, por exemplo, escutar o rugido do Cascumpus.

${ }^{6}$ Encenação: remete a possibilidade de o objeto ser controlado por um jogador co m seu dispositivo móvel.
} 
tem a missão de coletar o Tesouro. Assim, a condição pode ser: (Avatar pegou Tesouro) É importante enfatizar que no momento da criação dessa condição, os avatares já devem ter sido criados por meio do editor de jogadores.

- <avatar>:<ligação>:<atributoObjeto:refInstancia>: essa tripla permite que partes de um diálogo de um determinado personagem (instância de objeto) na aventura possa compor uma condição. Por exemplo, para o jogador ativar a missão de recuperar o Tesouro, o mesmo deve responder a seguinte opção de diálogo: "Sim, eu posso recuperar seu tesouro", para a personagem Alice (instância de objeto). A condição para a situação descrita é: (avatar falou confirmação:Alice). Sendo que atributoObjeto confirmação precisa ter uma referência há uma instância de objeto, neste caso Alice. O atributoObjeto abrange as seguintes situações:

o Diálogo Inicial: ocorre quando um jogador cumprimenta um personagem, sendo caracterizado por diálogos como: “Olá aventureiro", "Bom dia!”. O Diálogo Inicial é representado pelo atributoObjeto dialogoInicial:refInstancia;

○ Diálogo Final: ocorre quando o jogador finaliza o diálogo com um personagem, sendo caracterizado por diálogos como: "Muito obrigado!", 'Boa sorte!”. O Diálogo Final é representado pelo atributoObjeto dialogoFinal:refInstancia;

oDiálogo de Negação: ocorre quando o jogador se recusa a ajudar um personagem da aventura, por exemplo, "Aventureiro você pode capturar todas as galinhas soltas?", nesse contexto o Diálogo de Negação é 'Não! Sinto muito, estou ocupado com outra tarefa!". O Diálogo de Negação é representado pelo atributoObjeto negação:refInstancia;

o Diálogo de Confirmação: esse diálogo corre quando o jogador concorda em ajudar um personagem. Por exemplo, "Aventureiro você pode recuperar o tesouro roubado?", nesse contexto, recebendo a resposta "Sim! Será um prazer ajudar!". O Diálogo de Confirmação é representado pelo atributoObjeto confirmacao:refInstancia.

Finalmente, é importante enfatizar que toda instância de objeto que possui um diálogo, possui atributoObjeto definido como tipo="atributoObjeto" no script de diálogo, conforme visto na Figura 2. Além disso, o editor permite a composição de condições por meio dos operadores lógicos $A$ ND e OR.

\subsection{Editor de Comportamento}

Esse editor permite atribuir comportamento dinâmico em instâncias de objetos, por meio de agentes. Para tanto, a instância de objeto deve ter o atributo Encenação registrado como Agente. Para definir o comportamento dinâmico é necessário considerar um conjunto de informações, tais como:

- Posições geográficas: longitude, latitude e altitude que o objeto pode assumir de acordo com eventos da aventura; 
- Comportamento: pode ser agressivo, passivo, colaborativo ou competidor. Por exemplo, agressivo, a instância de objeto (Personagem) irá aparecer próximo ao jogador e roubar seu Tesouro; passivo remete a um comportamento no qual a instância de objeto (monstro) fica nas proximidades do jogador, fazendo que o mesmo escute um rugido (Sugestão) e tome decisões rápidas sob pressão; colaborativo, a instância de objeto pode colaborar o jogador por meio de mensagens; por fim, competidor, quando a instância de objeto dificulta a aventura do jogador, por meio de falsas dicas de ajuda (mensagens).

\subsection{Editor de Enredos}

Esse surgiu da necessidade de ajudar o jogador a analisar as informações sobre as decisões tomadas. Esse editor baseia-se no conceito de Storytelling, que apresenta eventos por meio de imagens e palavras, de modo a compor uma estória [MANGIONE et. al., 2011].

$\mathrm{O}$ uso desses elementos permite ao jogador construir conhecimento e significado sobre suas ações no jogo, de modo a contribuir para que o jogador tenha um melhor entendimento sobre as informações relacionadas com suas decisões. Isso ocorre, pois os enredos servem de feedback para o jogador, quando ele cumpre com uma condição ou missão. Finalmente, os Enredos são associados a condições e/ou missões. Assim quando uma missão ou condição é satisfeita, o Enredo associado é apresentado para o jogador.

\section{O Mistério do Tesouro de Marco Polo}

Nesse jogo, o jogador é colocado em situações em que ele precisa andar por ruas de uma cidade coletando pistas que the ajudem a recuperar uma edição rara e valiosa das "Viagens de Marco Polo" que vale milhões. Após coletar as pistas que leve o jogador até o ladrão (contratado por Carmen) que roubou a edição das "Viagens de Marco Polo", o mesmo conversa com o ladrão para recuperar a relíquia e concluir a missão.

Além disso, o jogo ensina ao jogador a gestão de tempo, já que o mesmo tem um determinado tempo para recuperar as pistas. As pistas são detalhes relacionados à região e a outros personagens do jogo, de modo que, o jogador associa a diversão do jogo com a investigação para recuperar a edição das "Viagens de Marco Polo"7 ${ }^{\text {" }}$ Os elementos definidos para essa Aventura são:

- Avatar: Detetive

- Objetos do tipo Personagem: Mensageiro, Cozinheiro, Porteiro e Merei Laroc. Todos com diálogos e proximidade de 15 metros.

- Objeto do tipo Item: a edição das "Viagens de Marco Polo" com proximidade de 10 metros.

\footnotetext{
7 é um diário que registra as viagens de Marco Polo ao longo da Ásia do Sul até a China.
} 
- Objetos do Tipo Limite Área Geográfica: Limite para restringir a área da aventura;

- Sugestão: áudio do mar que indica que o jogador está próximo de Merei Laroc.

A disposição das Instâncias de Objetos no mapa é apresentada na Figura 3. Primeiramente, tem-se a instância do Objeto Limite, delimita a área geográfica do jogo.

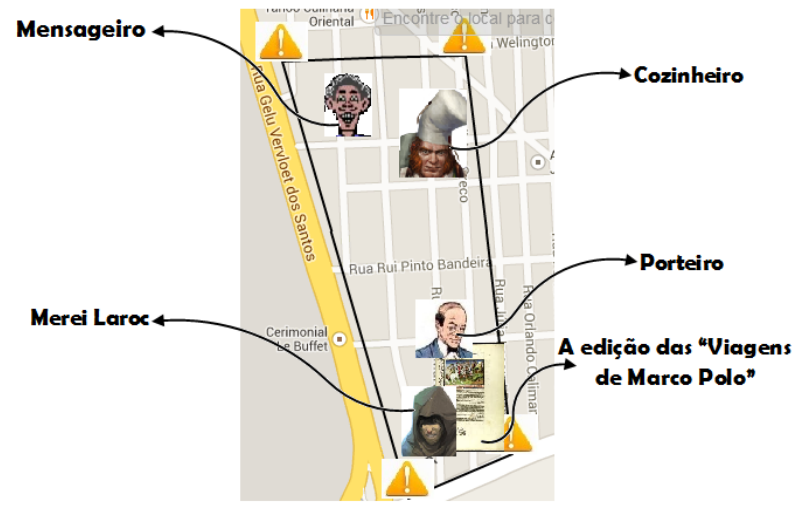

Figura 3: Disposição das Instâncias de Objetos

Ainda na Figura 3, no canto esquerdo superior tem-se o personagem Mensageiro, local onde o jogo será iniciado. Conseguinte, tem o personagem Cozinheiro que irá fornecer indicações para sobre o paradeiro do personagem Merei Laroc. Adiante, tem-se o personagem Porteiro que irá informar que o suspeito (Merei Laroc) gosta muito da brisa do mar. O personagem Merei Laroc se encontra próximo ao mar, na parte inferior do mapa. O jogador por meio do seu dispositivo móvel terá que conversar com os personagens, com o intuito de chegar ao ladrão e recuperar a edição das "Viagens de Marco Polo".

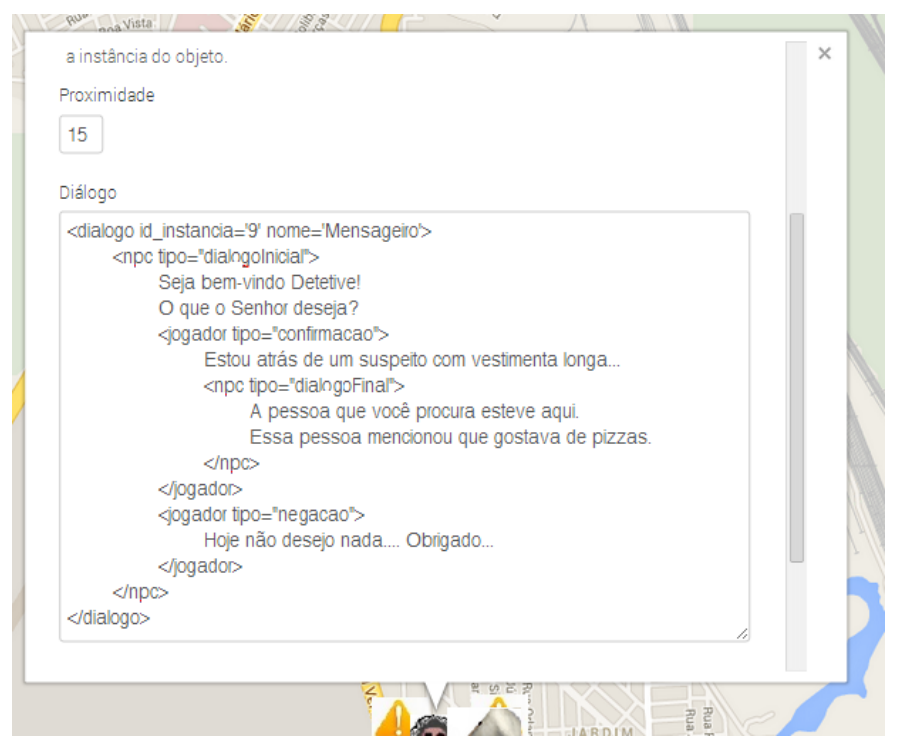

Figura 4:Edição da Instância de Objeto Mensageiro

A Figura 4 apresenta a configuração da Instância de Objeto do personagem Mensageiro, onde percebe-se a edição do script de diálogo que permite ao jogador escolher entre duas opções de diálogo com seu dispositivo móvel, são: "Estou atrás de um senhor com uma vestimenta longa...", que é uma parte do diálogo com o atributoObjeto="confirmação", e 
"Hoje não desejo nada... Obrigado..." com o atributoObjeto="negação". Adicionalmente, o personagem Mensageiro tem proximidade de 15 metros, sendo essa a distância necessária para o jogador conseguir vê-lo.

A par do exposto, as condições criadas para a Missão de recuperar a edição das "Viagens de Marco Polo" são provenientes dos diálogos com os personagens instanciados no mapa. As condições permitem avaliar se o jogador escolheu as opções de diálogos que permitem avaliar que o mesmo fez boas decisões. Em outras palavras, as condições para avaliar se o jogador conseguiu juntar todas as pistas para tomar boas decisões e chegar até o personagem Merei Loroc. Cada condição ao ser concluída faz soar um Enredo (Story) chamado Condição Completa, que é do tipo áudio. A missão e condições criadas são apresentadas na Figura 5. A missão Edição de Marco Polo é composta por 4 condições ligadas por meio do operador lógico AND e, após sua conclusão, o jogador recebe a instância do objeto "Edição das Viagens de Marco Polo".

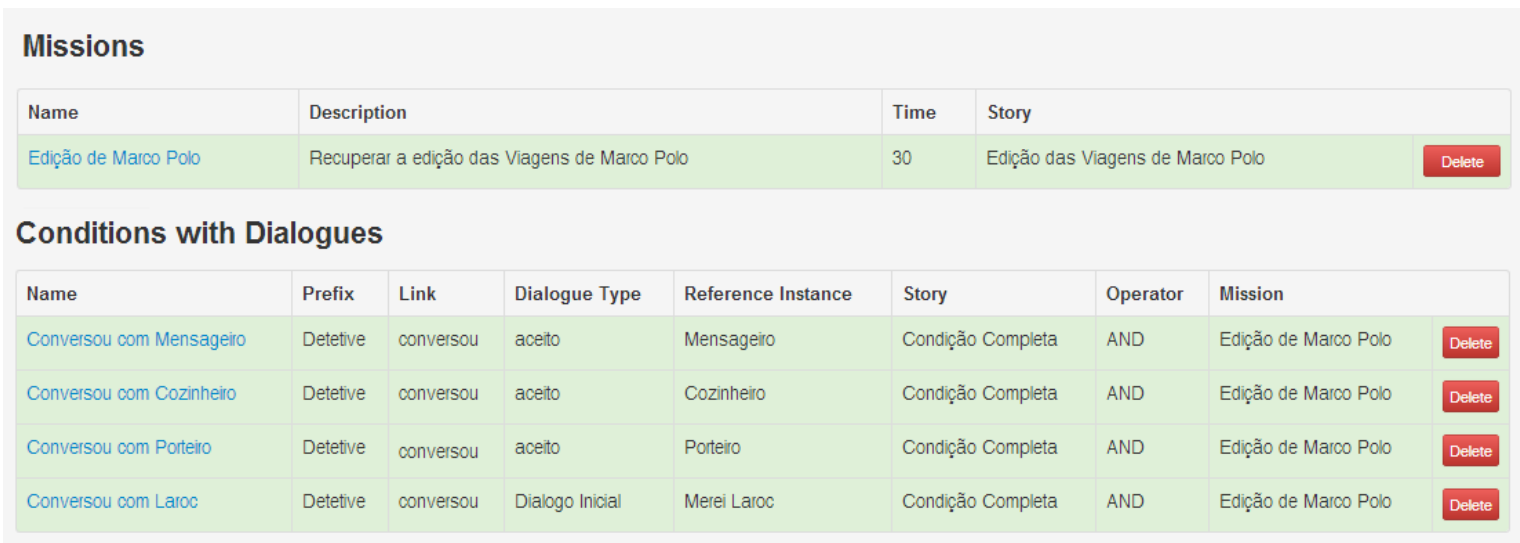

Figura 5: Missões e Condições para a Aventura de Marco Polo

Nessa aventura, é importante salientar que o jogador exercita/aprende os seguintes tipos de decisões [Orasanu, 1993]:

- Resource management: o jogador precisa passar por um conjunto de tarefas que consomem tempo para que seja possível encontrar o bandido e recuperar a edição das "Viagens de Marco Polo". Além disso, o jogador precisa ter um conhecimento mínimo da área geográfica do jogo.

- Option/response selection: durante o jogo, o jogador é confrontado com um conjunto de ações e opções a serem seguidas para solucionar o mistério da relíquia (problema), ou seja, encontrar a "Edição das Viagens de Marco Polo".

\section{Conclusões}

Este artigo apresenta os resultados de uma pesquisa sobre ambientes para a especificação de jogos que possam contribuir para o desenvolvimento de habilidades para a tomada de decisão. Uma vez que este artigo busca contribuições da informática para o desenvolvimento de habilidade humanas cognitivas. Assim, produz resultados que impactam em três áreas de conhecimento: computação, psicologia e educação. Ainda, contribui a abertura de uma nova 
área de aplicação de jogos locativos - os Jogos Locativos de Decisão para o desenvolvimento de habilidades para a tomada de decisão.

Foi proposto neste artigo um ambiente para a especificação de aplicações locativas que possuam elementos úteis para o desenvolvimento de habilidades cognitivas para tomada de decisão, com o uso de cenários simulados. Este é um desafio debatido na literatura, onde algumas das principais contribuições proveem recursos usados para treinamento de tomada de decisão em contextos limitados. Por fim, este artigo apresenta o conceito de LDG que possui um conjunto de características essenciais para um ambiente dinâmico que permita desenvolver habilidades de tomada de decisão com base em incertezas. No futuro, planejamos adaptar o ambiente para o estilo orientado a serviços, de modo a integrar de maneira interoperável com o executor de jogos em Android OS. Assim, tornando possível a realização de experimentos com alunos.

\section{Referências Bibliográficas}

ARIS. "ARIS - The Manual”, In: http:/three.umfglobal.org/resources/1857/ARISthemanual.pdf, Janeiro, 2013.

CAIRD-DALEY, A., DAWSON, B., CIERESZKO, R., OSBORNE, B., and PARKER, I. (2009)."Training Decision Making Using Serious Games: Requirements Analysis for Decision Making", In: HFI DTC, UK.

CHOEK, D., A., GOH, H., K., LIU, W., FARBIZ, F., FONG, W. S., TEO, S., L., LI, Y., YUNG, X. (2004) "Human Pacman: a mobile, wide-area entertainment system based on physical, social” In: Personal and Ubiquitous Computing, Volume 8, pp. $71-81$.

GEE. J. P., (2003)“What Video Games Have To Teach Us About Learning and Literacy”. New York: Palgrave Macmillan.

GUTIERREZ, L.; NIKOLAIDIS, I.; STROULIA, E.; GOUGLAS, S.; ROCKWELL, G.; BOECHLER, P.; CARBONARO, M.; KING, S., (2011) "fAR-PLAY: A framework to develop Augmented/Alternate Reality Games" In: PERCOM, IEEE.

KLEIN, G., ORASANU, J., CALDERWOOD, R., AND ZSAMBOK, C.E. (1993) "Decision Making in Action: Models and Methods." In: Ablex Publishing Co., Norwood, NJ.

MANGIONE, G.R.; ORCIUOLI, F.; PIERRI, A.; RITROVATO, P.; ROSCIANO, M., (2011) "A New Model for Storytelling Complex Learning Objects," Intelligent Networking and Collaborative Systems (INCoS), pp.836,841.

MARCH, J., G. (1994)“A Primer on Decision Making: How Decisions Happen”, NY.

ORASANU, J. M. (1993). Decision making in the cockpit. In: Wiener, E. L., Kanki, B. G. and Helmreich, R. L. (eds). Cockpit resource management. London: Academic Press Limited.

PRASOLOVA-FØRLAND, E,. FOMINYKH, M., DARISIRO, R., and MØRC, I,(2013) A.,: Training Cultural Awareness in Military Operations in a Virtual Afghan Village: A Methodology for Scenario Development. 46th Hawaii International Conference on System Sciences (HICSS), Wailea, HI, USA,IEEE, ISBN: 978-1-4577-1925-7.

MORATI JUNIOR, R. G.; TAVARES, O. L.; Menezes, C.S. "Authoring Environment for Location Decision Games for Decision-Making Skills Development". Advances in Intelligent Systems and Computing. 2ed.: Springer International Publishing, 2014, v. 2, p. 465-475,doi: 10.1007/978-3-319-05948-8_45 ,ISSN 2194-5357. 